\title{
COINCIDENCE OR CORRELATION: A 8 YEAR OLD GIRL WITH \\ CONCOMITANT INFECTION OF ENTEROBIUS VERMICULARIS (PINWORM INFECTION) AND EPSTEIN-BARR VIRUS (INFECTIOUS MONONUCLEOSIS)
}

\author{
M.sc. MD Elena Manoleva Nikolovska-Pediatrician, \\ MD Aleksandar Manolev-Specialist of Internal Medicine \\ Departments of Paediatrics and Internal Medicine, \\ PHI Polyclinic“MANOLEVI”, Skopje, Macedonia \\ emanoleva78@yahoo.com,amanolev@yahoo.com
}

\section{BACKGROUNDS AND AIMS}

Pinworm infection, also called enterobiasis, is caused by Enterobius vermicularis. E vermicularis is a white slender nematode with a pointed tail. In humans, they reside in the cecum, appendix and ascending colon. Transmission can occur via direct contact with contaminated furniture, bedclothes, bedding, towels, toilets, doorknobs or other objects. Pinworm infection is primarily a pediatric condition. Of all age groups, school-aged children (aged 5-9 years) are most at risk for pinworm infections. Incubation period is usually 1-2 months.

Infectious mononucleosis, refers to a group of symptoms usually caused by the Epstein-Barr virus (EBV). The virus is spread through direct contact with saliva from the mouth of an infected person or other bodily fluids such as blood. The virus has an incubation period of approximately four to eight weeks (1-2 months). The following groups have a higher risk for getting mono: young people between the ages of 15 and 30 , students, medical interns, nurses, caregivers and people who take medication that suppress the immune system.

\section{METHODS}

A 8 year old girl came on exam for symptom such as itching in the anal region, abdominal pain in last 2 months and the presence of worms in the stool. Physical examination revealed diffuse abdominal pain. Blood test were negative for leucocyte and CRP. First laboratory findings revealed normal hemoglobin, leukocytes and serum C-reactive protein and normal urine analysis. The crop culture was positive for Enterobius vermicularis. She received 3 days therapy with mebendazole.

Seven days after therapy, she came on exam with high fever, sore throat, swollen submandibular lymph nodes and abdominal pain. The liver and spleen weren't palpable under the right costal margin.

\section{RESULTS}

Ultrasonography of the abdomen confirmed normal liver and gallbladder, enlarged spleen for the age $(140 \mathrm{~mm})$, normal findings on kidneys and bladder. Crop culture was positive for Enterobius vermicularis. First laboratory findings revealed normal hemoglobin, leukocytes and serum C-reactive protein and normal urine analysis.

Second laboratory findings revealed: leukocytes 12,4 x $10^{\wedge} 9 / \mathrm{L} \quad$ with $\quad 14 \%$ neutrophils, $80 \%$ lymphocytes. Transaminases were elevated: AST 131...89 U/1, ALT 153...123 U/1. LDH 1375 U/L; CRP 18 mg/dl. Test for Epstein Barr virus and Cytomegalovirus were positive.

\section{CONCLUSIONS}

Pinworm infection and infectious mononucleosis are two different infectious disease caused by two completely different infectious microorganisms. The only similar and common characteristic is the same incubation period. Still, in this case, remains the question, is it the drop of the immune system the reason that made this girl sensitive to these different microorganism, or still, there is some connection between these two diseases.

\section{REFERENCES}

1.Johannsen EC Schooley RT Kaye KM. Epstein-Barr virus (infectious mononucleosis). In: Mandell GL, Bennet JE, Dolin $\mathrm{R}$, eds. Mandell, Douglas and Bennett's principles and practice of infectious diseases. Vol 2, 6th Ed. Philadelphia: Elsevier, 2005:1801-1820.

2. Crumpacker CS Wadhwa S. Cytomegalovirus. In: Mandell GL, Bennett JE, Dolin R, eds. Mandell, Douglas and Bennett's principles and practice of infectious diseases. Vol. 2, 6th Ed. Philadelphia: Elsevier, 2005:1786-1801.

3. Kucik CJ, Martin GL, Sortor BV. Common intestinal parasites. Am Fam Physician. 2004;69(5):1161-68. (PubMed) 